\title{
Functional Trait Trade-Offs for the Tropical Montane Rain Forest Species Responding to Light from Simulating Experiments
}

\author{
Peili Mao, ${ }^{1,2}$ Runguo Zang, ${ }^{2}$ Hongbo Shao, ${ }^{1,3}$ and Junbao Yu ${ }^{1}$ \\ ${ }^{1}$ Key Laboratory of Coastal Zone Environmental Processes, Yantai Institute of Coastal Zone Research, \\ Chinese Academy of Sciences (CAS), Yantai, Shandong 264003, China \\ ${ }^{2}$ Key Laboratory of Forest Ecology and Environment, The State Forestry Administration, Research Institute of Forest Ecology, \\ Environment and Protection, Chinese Academy of Forestry, Beijing 100091, China \\ ${ }^{3}$ Institute of Life Sciences, Qingdao University of Science \& Technology, Qingdao 266042, China
}

Correspondence should be addressed to Runguo Zang; zangrung@caf.ac.cn and Hongbo Shao; shaohongbochu@126.com

Received 15 May 2014; Accepted 24 May 2014; Published 11 June 2014

Academic Editor: Marian Brestic

Copyright (C) 2014 Peili Mao et al. This is an open access article distributed under the Creative Commons Attribution License, which permits unrestricted use, distribution, and reproduction in any medium, provided the original work is properly cited.

Differences among tropical tree species in survival and growth to light play a key role in plant competition and community composition. Two canopy species with contrasting functional traits dominating early and late successional stages, respectively, in a tropical montane rain forest of Hainan Island, China, were selected in a pot experiment under 4 levels of light intensity (full, $50 \%$, $30 \%$, and $10 \%$ ) in order to explore the adaptive strategies of tropical trees to light conditions. Under each light intensity level, the pioneer species, Endospermum chinense (Euphorbiaceae), had higher relative growth rate (RGR), stem mass ratio (SMR), specific leaf area (SLA), and morphological plasticity while the shade tolerant climax species, Parakmeria lotungensis (Magnoliaceae), had higher root mass ratio (RMR) and leaf mass ratio (LMR). RGR of both species was positively related to SMR and SLA under each light level but was negatively correlated with RMR under lower light ( $30 \%$ and $10 \%$ full light). The climax species increased its survival by a conservative resource use strategy through increasing leaf defense and root biomass investment at the expense of growth rate in low light. In contrast, the pioneer increased its growth by an exploitative resource use strategy through increasing leaf photosynthetic capacity and stem biomass investment at the expense of survival under low light. There was a trade-off between growth and survival for species under different light conditions. Our study suggests that tree species in the tropical rainforest adopt different strategies in stands of different successional stages. Species in the earlier successional stages have functional traits more advantageous to grow faster in the high light conditions, whereas species in the late successional stages have traits more favorable to survive in the low light conditions.

\section{Introduction}

In tropical rain forests, light is the most important limiting resource for tree seedling establishment, growth, and survival $[1-5]$. Shade tolerance plays a major role in plant community dynamics [5-10]. Two important hypotheses for species' shade tolerance have been proposed: carbon gain hypothesis [11] and stress tolerance hypothesis [12]. Carbon gain hypothesis defines shade tolerance as the maximization of net carbon gain together with the minimization of respiration costs for maintenance. However, carbon gain hypothesis has been challenged by some studies on tropical tree seedlings that have not found growth ranking reversals of different shade tolerance species in high and low light [1214]. Stress tolerance hypothesis thought of shade tolerance as maximization of the resistance to biotic and abiotic stresses in low light. Some new researches agreed with this hypothesis in recent years [13-17].

It has reached a consensus on the suites of traits that associate with shade tolerance, including leaf physiology and biochemistry, leaf anatomy and morphology, crown size, and whole plant architecture [10]. Pioneer species demonstrate 
higher metabolic rate, such as higher RGR, photosynthesis capacity, and respiration rate, than shade tolerant species [1822 ], which is disadvantageous for them to survive in the understory because their metabolic cost of maintaining high photosynthetic performance cannot be supported in low light environment [18]. Small seedlings of pioneer species allocate higher biomass to leaves in order to escape understory constraint by rapid growth $[12,23-25]$. On the contrary, shade tolerant species show higher root biomass allocation, which is advantageous for them to escape carbohydrate loss and increase their resprouting ability in the understory [26]. Specific leaf area is an important trait for plant shade tolerance, because it has close relationships with leaf photosynthetic rate, leaf span, and leaf defensive ability [12, 23, 27, 28]. However, some new studies suggested that wood density was a better trait indicating plant shade tolerance $[26,29]$.

Phenotypic plasticity is an important means for plants to cope with environmental heterogeneity [30, 31]. It was a striking trait associated with shade tolerance [10]. Plant plastic phenotypic responses can enhance light capture and photosynthetic efficiency in the shade [32]. In low light, plant species with higher plasticity show higher seedling mortality rate $[33,34]$. Morphological plasticity is an important feature of plants in natural communities. Some researchers reported that pioneer species had higher plasticity in morphology $[22,25,35]$. However, some other studies suggested the contrary conclusions [10, 36-38]. Coste et al. [39] indicated that plasticity of leaf traits between pioneer and shade tolerant species was similar. Rozendaal et al. [40] thought that pioneer species had higher plasticity in seedling stage not at adult stage. So, the relationship between plant plasticity and shade tolerance is complex.

The tropical rain forest on Hainan Island of China is one of the most important forest ecosystems, which has complex structure and rich biodiversity. A large percentage of tropical forests in China are tropical montane rainforests, especially on Hainan Island, which is in the most southern part of China and in the northern edge of tropical Asia [41]. However, the excessive deforestation and unreasonable land use have led to the large scale reduction of primary forest and formation of degraded ecosystems of different successional stages. The natural secondary forest, developing after the primary forest was destroyed, has become the most important forest resources in Hainan Island. There have been many studies on the composition, structure, and dynamics on the tropical montane rain forest of Hainan Island, but few studies have been carried out on the ecophysiology of trees in the forest, which is the basis to further explore the function and dynamics of the forest ecosystems. Studies on the ecophysiology of tree seedlings in different successional stages could help us to understand the mechanism of tree replacement and the relationships between trees and their environment.

In this paper, seedlings of two representative tree species (Endospermum chinense (Ec) and Parakmeria lotungensis (Pl)) distributed in the tropical montane rain forest on Hainan Island were selected and their ecological adaptation to light was studied. We measured some of the growth and morphological traits of the two species for seedlings under different light levels by the pot experiments. The objectives of the study were to explore the following questions: (1) whether light intensity had any significant influence on the performance of tree species in terms of growth and morphological traits, (2) whether the ecological adaptation strategies to light for the two tree species differed significantly, (3) whether irradiance-elicited morphological plasticity differed among the two species, and (4) whether there were any trade-offs between growth and survival related traits under different light conditions.

\section{Materials and Methods}

2.1. Study Area. The study was carried out in the Jianfengling forest region of Hainan Island, and our pot experiments were conducted at the Jianfengling Experimental Center of The Research Institute of Tropical Forestry, Chinese Academy of Forestry (latitude $18^{\circ} 42^{\prime} \mathrm{N}$; longitude $108^{\circ} 49^{\prime} \mathrm{E}$; altitude $80 \mathrm{~m}$ ). The tropical montane rain forest in Jianfengling is distributed from 700 to $1100 \mathrm{~m}$ in altitude, which possesses the largest area and the richest species in the Jianfengling forest region. The tropical montane rain forest area in Jianfengling has a mean annual air temperature of $19.7^{\circ} \mathrm{C}$. The rainfall averages $2651.3 \mathrm{~mm}$ per year. Mean annual relative humidity is $88 \%$. The forest is mainly composed of tree species from the families of Lauraceae, Rubiaceae, Fagaceae, and Myrtaceae.

2.2. Study Species. Two evergreen canopy tree species of the tropical montane rain forest were selected due to the limitation of seeds and seedlings. According to the experiences of local foresters and our observations in the forest region, $E$. chinense (Ec, Euphorbiaceae) was regarded as the representative species of pioneer or early successional stage, which was common in the natural secondary forest stands. It is a light demanding pioneer species dominating the early successional stage of the tropical montane rainforest and can be found frequently in the large canopy openings and disturbed areas. Its maximum height is above $30 \mathrm{~m}$. However, P. lotungensis (Magnoliaceae) is a shade tolerant climax species dominating the old growth stands of the tropical montane rainforest. It is distributed in fertile broad-leaved forest. It can regenerate well under closed canopy. Its maximum height also is above $30 \mathrm{~m}$. Ec is a fast growing species, which plays important roles in the carbon sequestration of secondary forest; meanwhile, its timber can be used for firewood and utensil makings. $\mathrm{Pl}$ is a slower growing hardwood with higher wood density, which has high quality timber for industrial and civil use. Ecologically, the dominant role played by $\mathrm{Pl}$ in later successional stages of the tropical montane rainforest makes it a paramount species in carbon storage and functioning of the forest ecosystems. These two species are important species both ecologically and economically in this tropical forest area, which is one of the reasons why we select them for this experimental study. The classification of the tree species into early versus late successional groups was only based on experiences and observations but had no ecophysiological basis, which is just one of the objectives of this experimental study. 
TABLE 1: Seedling traits, abbreviations, and units for growth and morphological analysis. These parameters were calculated following Poorter [42] and Bloor and Grubb [43].

\begin{tabular}{|c|c|c|}
\hline Traits & Abbreviation & Units \\
\hline Relative growth rate $\left(\ln W_{2}-\ln W_{1}\right) /\left(T_{2}-T_{1}\right)$ & RGR & $\mathrm{mgg}^{-1} \mathrm{~d}^{-1}$ \\
\hline Relative height growth rate $\left(\ln H_{2}-\ln H_{1}\right) /\left(T_{2}-T_{1}\right)$ & $\mathrm{RGR}_{H}$ & $\mu \mathrm{m} \mu \mathrm{m}^{-1} \mathrm{~d}^{-1}$ \\
\hline Leaf mass rate (leaf dry mass/total seedling dry mass) & LMR & $\mathrm{gg}^{-1}$ \\
\hline Stem mass rate (stem + petiole mass)/total plant mass & SMR & $\mathrm{gg}^{-1}$ \\
\hline Root mass rate (root dry mass/total seedling dry mass) & RMR & $\mathrm{gg}^{-1}$ \\
\hline Specific leaf area (leaf area/leaf mass) & SLA & $\mathrm{cm}^{2} \mathrm{~g}^{-1}$ \\
\hline Leaf area ratio (total leaf area/total seedling dry mass) & LAR & $\mathrm{cm}^{2} \mathrm{~g}^{-1}$ \\
\hline
\end{tabular}

$W$ is seedling dry mass $(\mathrm{g}), H$ is seedling height $(\mathrm{cm}), A$ is seedling leaf area $\left(\mathrm{cm}^{2}\right)$, and $T$ is time (d). Subscripts refer to initial (1) or final (2) harvest.

2.3. Experimental Design. Plants were grown at four different light levels. Three shade chambers were created by cement poles. Three light levels were created by covering the shade chambers with an increasing number of layers of neutral shade netting [42]. The daily course of incident photon flux density (PFD) was measured with an open portable photosynthesis system (LI-6400; Li-Cor, Inc., Lincoln, NE) in March 2005. PFD was measured every two hours from 10:00 to 18:00 o'clock in three cloudless days. The four light levels were about $100 \%, 50 \%, 30 \%$, and $10 \%$ full light.

Mature seeds of the study species were collected from numerous mother plants in the tropical montane rain forest of Jianfengling Nature Reserve. After seeds were germinated, seedlings were grown in 30\% full light in the nursery near the Jianfengling Experimental Center for 8 months. Fifty healthy trees of each species were selected and transplanted to $9.1 \mathrm{~L}$ white plastic pots (one seedling per pot) on March 30,2005 . Then, these seedlings were placed under $30 \%$ full light to revive for about $50 \mathrm{~d}$ until they grew new leaves. After this, twelve individuals per species were moved to each light treatment on May 20, 2005 [2]. All seedlings were watered well. Positions of the pots were designed regularly. No seedlings died during the experiment.

At the time of moving, a sample from the seedlings ( $N=$ 5 per species) was harvested to measure initial patterns of biomass partitioning. Seedlings were separated into leaves, stems, and roots. Leaf area was measured with a leaf area meter (LI-3000A, Li-Cor, Inc., USA) and the material was oven dried at $70^{\circ} \mathrm{C}$ to constant weight and weighed to the nearest $0.01 \mathrm{~g}$. Regression equations based on leaf area and leaf maximum width of the initial harvested seedlings were used to estimate the leaf area of unharvested seedlings.

After the experiment ended on March 3, 2006, all seedlings were harvested and each was separated into leaf, stem, and root components. Leaf area was calculated by regression equations, and seedlings were dried at $70^{\circ} \mathrm{C}$ to constant weight and weighed to the nearest $0.01 \mathrm{~g}$. Seedling height and leaf maximum width were recorded at the start and end of the experiment. Branch number of each seedling was counted at the end of the experiment. From the harvest data, the morphological and growth indexes were derived (Table 1). The plastic index was calculated according to Valladares et al. [35] by the following formula: Plastic index $($ of a feature $)=($ maximum - minimum $) /$ maximum .
2.4. Data Analysis. Two-way analysis of variance (ANOVA) was used to analyze the effects of light, species, and their interaction on each of the dependent variables. The least significant difference (LSD) multiple comparisons were performed to permit separation of effect means at significant level of $P<0.05$. Correlation analyses were used to investigate relationships between RGR and other variables under each light level. All statistics were carried out using the SPSS for Windows 13.0 (SPSS, Chicago, IL, USA).

\section{Results}

3.1. Growth Rate. Light intensity showed significant effects on relative growth rate (RGR; $F=9.08 ; P<0.01$; Figure $1(\mathrm{a})$ ). RGR decreased with the decrease of light intensity. RGR in $100 \%$ was similar to that in $50 \%$ full light $(P>0.05)$, and they were significantly higher than that in $10 \%$ full light $(P<$ 0.01). However, light intensity showed no significant effects on relative height growth rate $\left(\mathrm{RGR}_{H} ; F=2.51 ; P=0.08\right.$; Figure 1(b)). There were significant differences in $\operatorname{RGR}(F=$ 327.98, $P<0.01)$ and $\operatorname{RGR}_{H}(F=420.24, P<0.01)$ between the species. Ec showed higher RGR $(P<0.01)$ and $\mathrm{RGR}_{H}$ $(P<0.01)$. In $10 \%$ full light, RGR and $\mathrm{RGR}_{H}$ for $\mathrm{Pl}$ were $0.11 \pm$ $0.02 \mathrm{mg} \cdot \mathrm{g}^{-1} \cdot \mathrm{d}^{-1}$ and $0.19 \pm 0.15 \mu \mathrm{m} \cdot \mu \mathrm{m}^{-1} \cdot \mathrm{d}^{-1}$, respectively, which suggested that the light-compensation point for $\mathrm{Pl}$ to grow was about $10 \%$ of full light. The interaction between light and species was significant for RGR $(F=5.10, P<0.01)$ but not for $\mathrm{RGR}_{H}(F=0.91, P=0.45)$. With decreasing light intensity, RGR for Ec decreased more slowly than Pl.

3.2. Biomass Allocation. Among the light levels, leaf mass rate (LMR; $F=5.04 ; P<0.01)$ and root mass rate (RMR; $F=5.43 ; P<0.01)$ differed significantly, whereas stem mass rate $(\mathrm{SMR})$ did not $(F=0.30, P=0.83)$. As the light intensity decreased, the two species increased LMR and decreased RMR, while their SMR did not vary obviously (Figure 2). The results showed that investment was made in stem biomass in low light at the cost of investment in root biomass. The two species differed significantly in $\operatorname{LMR}(F=$ 42.51, $P<0.01)$, SMR $(F=57.71, P<0.01)$, and RMR $(F=9.25, P<0.01)$. Compared with $\mathrm{Pl}$, Ec had lower LMR $(P<0.01)$ and $\operatorname{RMR}(P<0.01)$ and higher SMR $(P<0.01)$, which showed a typical shade-avoidance and light exploitative strategy. However, the interaction between light 


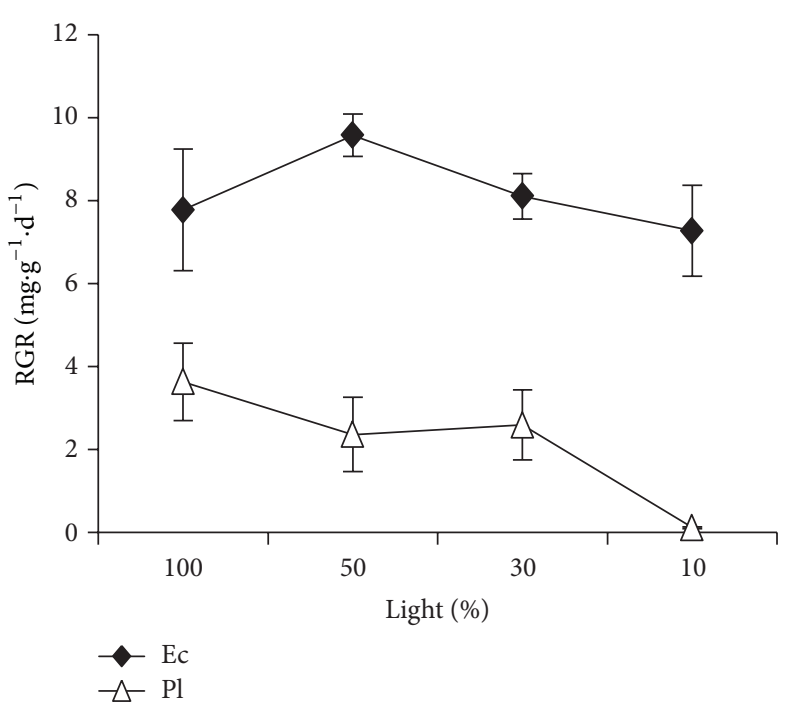

(a)

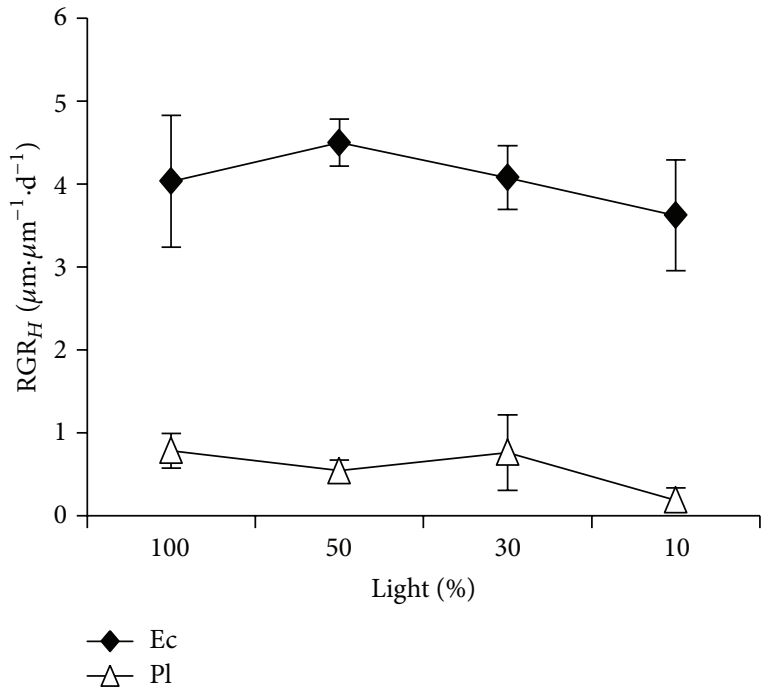

(b)

FIGURE 1: Growth rate responses to light for two rain forest tree species. Figures refer to (a) relative growth rate and (b) relative height growth rate.

and species was not significant for $\operatorname{LMR}(F=1.40, P=0.27)$, $\operatorname{SMR}(F=1.75, P=0.18)$, and $\operatorname{RMR}(F=0.52, P=0.67)$.

3.3. Leaf Morphology. There were significant differences for specific leaf area (SLA; $F=4.77 ; P<0.01)$ and leaf area ratio (LAR; $F=13.17 ; P<0.01$ ) among the light levels. SLA and LAR increased with the decrease of light intensity (Figure 3), and they showed the highest values in 10\% full light $(P<0.05)$. Ec showed higher SLA than $\mathrm{Pl}(F=48.11$; $P<0.01$; Figure 3). However, Ec was similar to $\mathrm{Pl}$ in LAR $(F=0.72 ; P=0.40$; Figure 3$)$. The interaction between light and species was significant for SLA $(F=3.67, P<0.05)$ and LAR $(F=3.54, P<0.05)$. With decreasing light intensity, Ec increased more rapidly than Pl in SLA and LAR.

3.4. Relationships between Growth Rate and Leaf Morphology. Morphological traits were strongly related to growth (Table 2). RGR was significantly positively related to SMR and SLA (except in 50\% full light) and negatively correlated with LMR (except in 10\% full light) under different light levels. Moreover, RGR was negatively correlated with RMR under $30 \%$ and $10 \%$ full light.

3.5. Morphological Plasticity. Leaf morphological plasticity was higher than biomass allocation plasticity (Table 3), which indicated that the change of organ forms was the major mode for plant species to adapt to different light environmental conditions. As a whole, Ec had higher morphological plasticity than $\mathrm{Pl}$ among measured traits.

\section{Discussion}

The response of growth rate to environmental factors demonstrates different life-history strategies of tropical tree species $[4,27]$. As the light intensity decreased, RGR of the two species decreased, suggesting they were light demanding but having different degrees of shade tolerance $[22,44]$. Ec showed higher RGR and $\mathrm{RGR}_{H}$ than $\mathrm{Pl}$. Higher growth rate provides a competitive advantage for species to escape quickly from the competition of surrounding species, especially higher height growth rate $[45,46]$. So, Ec was more shade intolerant than $\mathrm{Pl}$. Wood density was an important trait suggesting plant growth strategies [29]. Plant species with low wood density show higher growth rate and mortality rate in understory, while plant species with high wood density possess lower growth rate and higher survival rate [47, 48]. Air-dry density was 0.4 for Ec [49] and 0.6 for Pl [50], respectively. So, Pl invested more defense than Ec in order to increase its survival rate in understory. Higher growth rate and low wood density suggested that Ec was less shade tolerant than $\mathrm{Pl}$.

Biomass allocation patterns to leaves, stems, and roots in plants demonstrate their adaptive strategies in different environmental conditions [51]. With the decrease of light intensity, the two species increased LMR, SLA, and LAR at the expense of roots in ways that contributed to the light interception ability [51, 52]. Ec had lower LMR and higher SLA, while Pl had higher LMR and lower SLA. Eventually, Ec was similar to $\mathrm{Pl}$ in LAR, indicating that there was no significant difference between them in light interception ability. Ec had higher SMR under each light level, indicating that it had an obviously shade-avoidance strategy [53]. Pl showed higher RMR, which was advantageous for them to escape carbohydrate lost, improve their resprouting ability, and increase survival rate in the understory [27]. However, RMR was negatively correlated with RGR. So, higher investment in root biomass for $\mathrm{Pl}$ did decrease its growth rate.

SLA is an important trait for plant to grow and survive in different light environments [54]. Ec had higher SLA, which was positively related to RGR in each light level. 


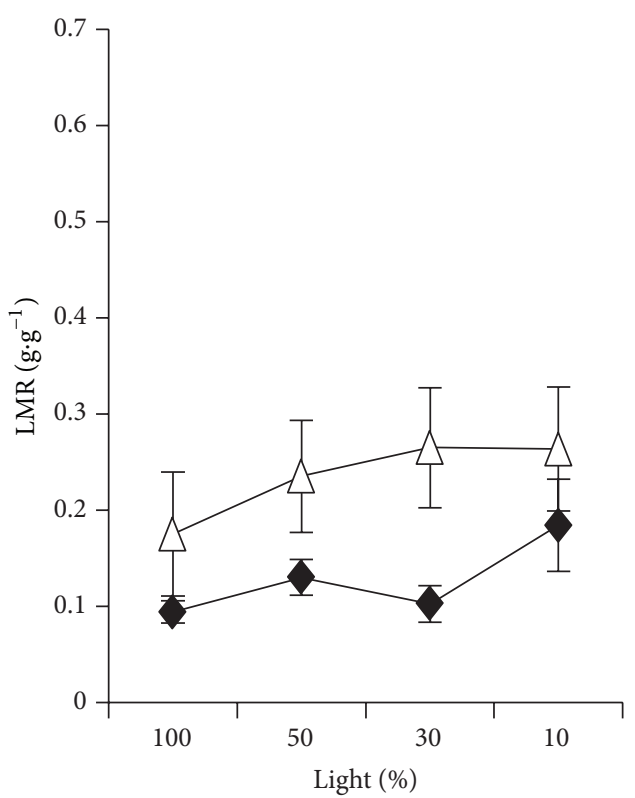

(a)

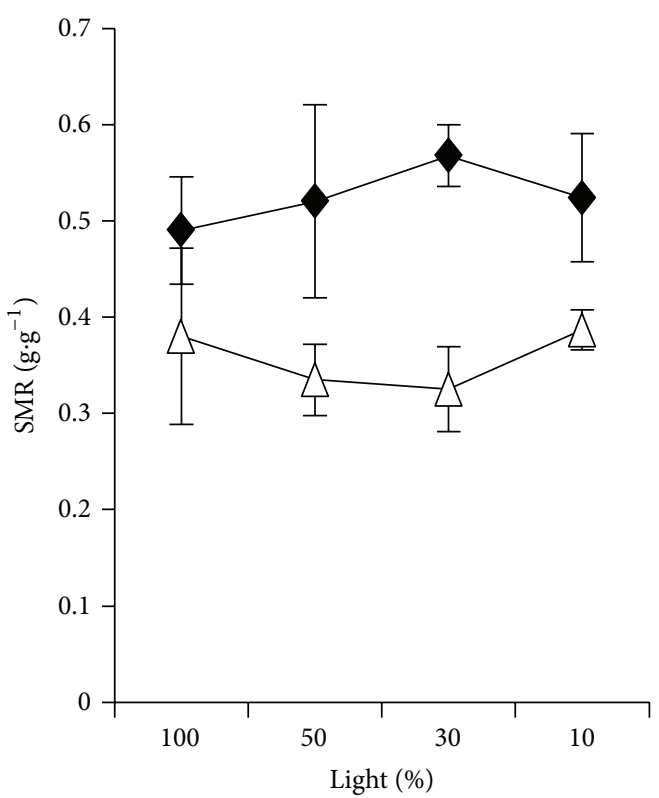

(b)

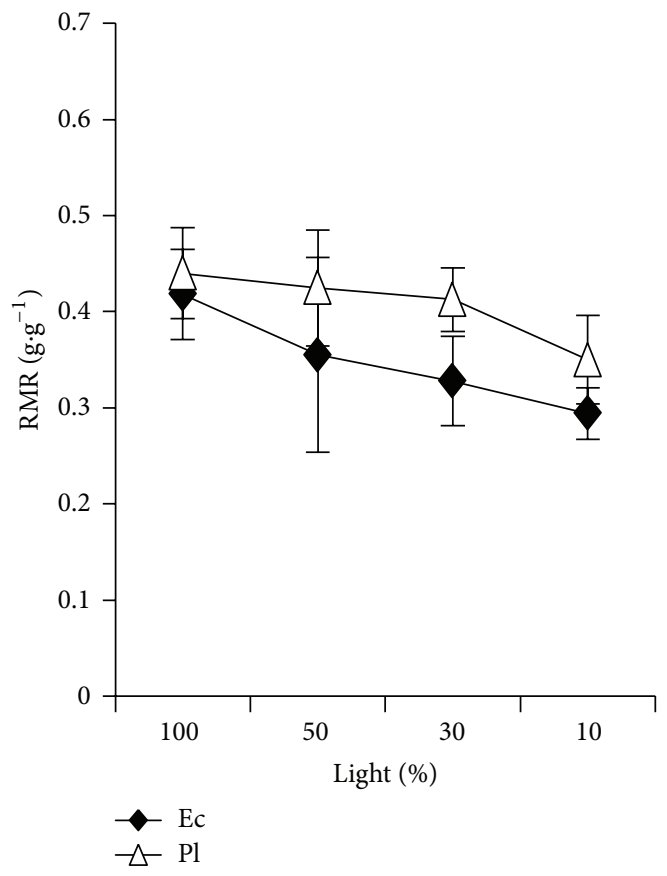

(c)

FIGURE 2: Biomass allocation responses to light for two rain forest tree species. Figures refer to (a) leaf mass ratio, (b) stem mass ratio, and (c) root mass ratio.

Higher SLA indicated higher photosynthetic capacity [19, 29, $55,56]$. Indeed, we did find that Ec had higher maximum net assimilation rate than Pl [57]. However, higher SLA did not favor Ec survival in low light due to low leaf defense ability. Salgado-Luarte and Gianoli [17] found that herbivory decreased the survival of the pioneer species Aristotelia chilensis (Elaeocarpaceae) in the forest understory but not in the canopy gaps. Pl had lower SLA than Ec, especially in $10 \%$ full light. Low SLA increased leaf defenses and leaf life span
$[12,14-17,23,27]$, which was advantageous for Pl to survive in low light. Moreover, longer leaf life span would help plant to accumulate an extensive leaf area eventually and increase light interception ability in low light [23]. So, low SLA was an important regeneration manner for $\mathrm{Pl}$.

Morphological plasticity is an important means by which plants cope with environmental heterogeneity. In this paper, plasticity of different organs was higher than biomass allocation, which was similar to the results of Bloor and Grubb [43]. 


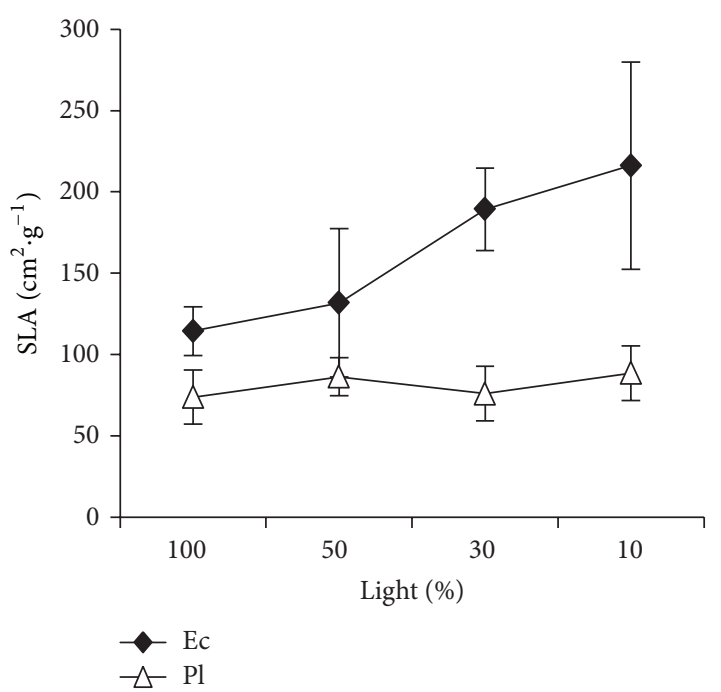

(a)

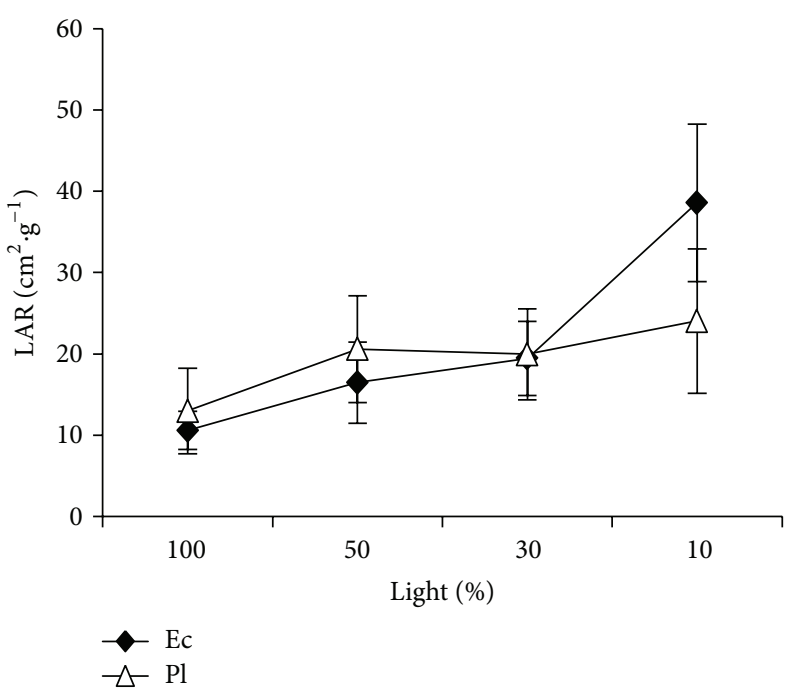

(b)

FIGURE 3: Leaf morphology responses to light for two rain forest tree species. Figures refer to (a) specific leaf area and (b) leaf area ratio.

TABLE 2: Correlations between growth rate and other measured variables in different light levels. Correlations significant at $P<0.05$ are shown in bold.

\begin{tabular}{lccccc}
\hline Light intensity & LMR & SMR & RMR & SLA & LAR \\
\hline 100\% full light & $\mathbf{- 0 . 6 8}$ & $\mathbf{0 . 7 4}$ & -0.50 & $\mathbf{0 . 6 7}$ & -0.37 \\
50\% full light & $\mathbf{- 0 . 8 1}$ & $\mathbf{0 . 8 1}$ & -0.44 & 0.62 & -0.38 \\
30\% full light & $-\mathbf{0 . 9 2}$ & $\mathbf{0 . 9 7}$ & $\mathbf{- 0 . 7 4}$ & $\mathbf{0 . 8 9}$ & -0.22 \\
$10 \%$ full light & -0.63 & $\mathbf{0 . 8 3}$ & $\mathbf{- 0 . 7 2}$ & $\mathbf{0 . 8 6}$ & $\mathbf{0 . 7 2}$ \\
\hline
\end{tabular}

The reason was perhaps that their adjustments could be achieved relatively cheaply $[11,43]$. Ec showed higher morphological plasticity than $\mathrm{Pl}$, which was in accordance with their shade tolerance degrees. And many researches also agreed that pioneer species had higher morphological plasticity than shade tolerant species $[22,25,35]$. Less plasticity for shade tolerant species to light is part of a general suite of traits associated with a conservative use of resources and a strong tolerance of low light stress [58]. Of course, some studies revealed that shade tolerant species had higher morphological plasticity $[10,36-38]$. The conflict between shade tolerance and plasticity was perhaps caused by the selection of functional traits. So, how to select traits was important for us to compare the plasticity of different plant species.

The two tree species showed different adaptive strategies to light at different successional stages in the tropical montane forest on Hainan Island. Pioneer functional group, represented by Ec, showed higher light requirement. Higher photosynthetic capacity and biomass investment in stem favor them to grow faster and gain more light resources in high light environment. Moreover, high morphological plasticity favors them to acclimate to the dynamic light environments. However, low defensive ability due to higher SLA and lower RMR decreased their survival in low light. Late
TABle 3: Plasticity indexes for morphological parameters in seedlings of the three rain forest tree species under different light levels.

\begin{tabular}{lccc}
\hline Indexes & \multicolumn{3}{c}{ Plasticity indexes } \\
& Ec & Pl & Mean \\
\hline Biomass allocation & & & \\
$\quad$ LMR & $0.49 \pm 0.20$ & $0.34 \pm 0.03$ & 0.42 \\
SMR & $0.14 \pm 0.07$ & $0.16 \pm 0.06$ & 0.15 \\
RMR & $0.30 \pm 0.04$ & $0.20 \pm 0.03$ & 0.25 \\
Biomass allocation mean & 0.31 & 0.23 & 0.27 \\
Leaf morphology & & & \\
$\quad$ SLA & $0.47 \pm 0.12$ & $0.17 \pm 0.06$ & 0.32 \\
$\quad$ LAR & $0.73 \pm 0.13$ & $0.46 \pm 0.04$ & 0.60 \\
Leaf morphological mean & 0.60 & 0.32 & 0.46 \\
Total & $\mathbf{2 . 1 3}$ & $\mathbf{1 . 3 3}$ & \\
\hline
\end{tabular}

successional functional group, represented by $\mathrm{Pl}$, demonstrated stronger defensive ability. Higher root allocation and tough leaves enhance their survivorship in the understory. Higher investment in root and leaf structure decreased the increment of leaf area and led to decreasing growth rate. Although the regeneration of $\mathrm{Pl}$ needed higher light intensity, longer life span after it reached the canopy made it exist in the old growth forest, such as long-lived Eucryphia cordifolia [59]. The above discussions on our study results suggest that a trade-off between growth and survival exists in tree species in the tropical montane rainforest of Hainan Island, and our results support the stress tolerance hypothesis.

The trade-off between growth and morphological traits means that early successional species increased their abilities of high growth to adapt to the high light environment through traits regulations, such as increasing SLA, SMR, and plasticity. However, this sort of traits regulations to increase growth rate could increase the risks of death such as animal herbivory, 
drought stress, and blowdown by typhoon, resulting in a lower survival rate. On the contrary, the climax species regulate their traits (such as decreasing SLA, while increasing RMR and LMR) so as to increase survival under the low light level understory at the expense of growth increment. The variations in the measured traits for the two species suggest that the tree species in this tropical montane rainforest have a trade-off in traits and growth rates under different levels of light intensity.

Differences in the ecological adaptive strategies among different functional groups at different stages provide the evidences for the maintenance of biological diversity in the tropical montane rain forest on Hainan Island. Since there are more than 700 tree species in this tropical montane rainforest, it is almost impossible to study the ecophysiological traits for each of them. The functional group approach is one of the ways to understand the ecology of tropical rainforest communities. There are varied ways for functional group identifications in tropical forests [60-65]. Species with similar morphological, phonological, or physiological traits can usually be categorized into the same functional group. In order to probe the characteristics (especially related with physiology) of the functional group, typical representative species from the group could be selected as the study subjects. The characteristics of the representatives can reflect the characteristics of the functional group. In this study, the two species were selected to represent the early and late successional stages of the tropical montane rainforest. They belong to the early successional functional group and late successional group, respectively. There are evidences (such as the morphological, distributional, and phonological similarities between the two representing species) that other species can be grouped into these two functional groups [6165]. The species belonging to the early successional functional group include Castanopsis fissa (Fagaceae), Schima superba (Theaceae), and Evodia glabrifolia (Rutaceae), while those belonging to the late successional group include Michelia mediocris (Magnoliaceae), Alseodaphne hainanensis (Lauraceae), and Beilschmiedia laevis (Lauraceae).

\section{Conclusion}

Through traits regulations, pioneer and climax species could adapt to their own environment, making them occupy different sites or successional stages in the region, and different groups of species could partition their niche in both space and time. Consequently, the species with differing characteristics could coexist in the tropical montane rain forest region. The biodiversity of the forest region could be maintained.

\section{Conflict of Interests}

The authors declare that there is no conflict of interests regarding the publication of this paper.

\section{Acknowledgment}

This study was supported by the Key Project of National Natural Science Foundation of China (30430570).

\section{References}

[1] R. L. Chazdon and N. Fetcher, "Photosynthetic light environments in a lowland tropical rain forest in Costa Rica," Journal of Ecology, vol. 72, no. 2, pp. 553-564, 1984.

[2] V. K. Agyeman, M. D. Swaine, and J. Thompson, "Responses of tropical forest tree seedlings to irradiance and the derivation of a light response index," Journal of Ecology, vol. 87, no. 5, pp. 815$827,1999$.

[3] B. Kyereh, M. D. Swaine, and J. Thompson, "Effect of light on the germination of forest trees in Ghana," Journal of Ecology, vol. 87, no. 5, pp. 772-783, 1999.

[4] N. Rüger, U. Berger, S. P. Hubbell, G. Vieilledent, and R. Condit, "Growth strategies of tropical tree species: disentangling light and size effects," PLoS ONE, vol. 6, no. 9, Article ID e25330, 2011.

[5] A. Jakovac, T. V. Bentos, R. C. G. Mesquita, and G. B. Williamson, "Age and light effects on seedling growth in two alternative secondary successions in central Amazonia," Plant Ecology \& Diversity, vol. 7, pp. 349-358, 2014.

[6] J. S. Denslow, "Tropical rainforest gaps and tree species diversity," Annual Review of Ecology and Systematics, vol. 18, pp. 431451, 1987.

[7] M. D. Swaine and T. C. Whitmore, "On the definition of ecological species groups in tropical rain forests," Vegetatio, vol. 75, no. 1-2, pp. 81-86, 1988.

[8] M. B. Walters and P. B. Reich, "Are shade tolerance, survival, and growth linked? Low light and nitrogen effects on hardwood seedlings," Ecology, vol. 77, no. 3, pp. 841-853, 1996.

[9] L. Poorter and E. J. M. M. Arets, "Light environment and tree strategies in a Bolivian tropical moist forest: an evaluation of the light partitioning hypothesis," Plant Ecology, vol. 166, no. 2, pp. 295-306, 2003.

[10] F. Valladares and Ü. Niinemets, "Shade tolerance, a key plant feature of complex nature and consequences," Annual Review of Ecology, Evolution, and Systematics, vol. 39, pp. 237-257, 2008.

[11] T. J. Givnish, "Adaptation to sun and shade: a whole-plant perspective," Australian Journal of Plant Physiology, vol. 15, no. 1-2, pp. 63-92, 1988.

[12] K. Kitajima, "Relative importance of photosynthetic traits and allocation patterns as correlates of seedling shade tolerance of 13 tropical trees," Oecologia, vol. 98, no. 3-4, pp. 419-428, 1994.

[13] M. B. Walters and P. B. Reich, "Low-light carbon balance and shade tolerance in the seedlings of woody plants: do winter deciduous and broad-leaved evergreen species differ?" New Phytologist, vol. 143, no. 1, pp. 143-154, 1999.

[14] C. H. Lusk, M. M. Pérez-Millaqueo, F. I. Piper, and A. Saldaña, "Ontogeny, understorey light interception and simulated carbon gain of juvenile rainforest evergreens differing in shade tolerance," Annals of Botany, vol. 108, no. 3, pp. 419-428, 2011.

[15] K. Kitajima, A.-M. Llorens, C. Stefanescu, M. V. Timchenko, P. W. Lucas, and S. J. Wright, "How cellulose-based leaf toughness and lamina density contribute to long leaf lifespans of shadetolerant species," New Phytologist, vol. 195, no. 3, pp. 640-652, 2012.

[16] K. Kitajima and L. Poorter, "Tissue-level leaf toughness, but not lamina thickness, predicts sapling leaf lifespan and shade 
tolerance of tropical tree species," New Phytologist, vol. 186, no. 3, pp. 708-721, 2010.

[17] C. Salgado-Luarte and E. Gianoli, "Herbivory may modify functional responses to shade in seedlings of a light-demanding tree species," Functional Ecology, vol. 25, no. 3, pp. 492-499, 2011.

[18] J.-W. Chen, Q. Zhang, X.-S. Li, and K.-F. Cao, "Steady and dynamic photosynthetic responses of seedlings from contrasting successional groups under low-light growth conditions," Physiologia Plantarum, vol. 141, no. 1, pp. 84-95, 2011.

[19] P. B. Reich, M. B. Walters, M. G. Tjoelker, D. Vanderklein, and C. Buschena, "Photosynthesis and respiration rates depend on leaf and root morphology and nitrogen concentration in nine boreal tree species differing in relative growth rate," Functional Ecology, vol. 12, no. 3, pp. 395-405, 1998.

[20] D. D. Kneeshaw, R. K. Kobe, K. D. Coates, and C. Messier, "Sapling size influences shade tolerance ranking among southern boreal tree species," Journal of Ecology, vol. 94, no. 2, pp. 471-480, 2006.

[21] J. L. Baltzer and S. C. Thomas, "Determinants of whole-plant light requirements in Bornean rain forest tree saplings," Journal of Ecology, vol. 95, no. 6, pp. 1208-1221, 2007.

[22] B. Lin and Q. Liu, "Plasticity responses of 4 tree species in subalpine-coniferous-forest to different light regimes," Acta Ecologica Sinica, vol. 28, no. 10, pp. 4665-4675, 2008.

[23] C. H. Lusk, "Leaf area and growth of juvenile temperate evergreens in low light: species of contrasting shade tolerance change rank during ontogeny," Functional Ecology, vol. 18, no. 6, pp. 820-828, 2004.

[24] C. H. Lusk and F. I. Piper, "Seedling size influences relationships of shade tolerance with carbohydrate-storage patterns in a temperate rainforest," Functional Ecology, vol. 21, no. 1, pp. 7886, 2007.

[25] A. Portsmuth and Ü. Niinemets, "Structural and physiological plasticity in response to light and nutrients in five temperate deciduous woody species of contrasting shade tolerance," Functional Ecology, vol. 21, no. 1, pp. 61-77, 2007.

[26] L. Poorter, K. Kitajima, P. Mercado, J. Chubiña, I. Melgar, and H. H. T. Prins, "Resprouting as a persistence strategy of tropical forest trees: relations with carbohydrate storage and shade tolerance," Ecology, vol. 91, no. 9, pp. 2613-2627, 2010.

[27] K. Seiwa and K. Kikuzawa, "Close relationship between leaf life span and seedling relative growth rate in temperate hardwood species," Ecological Research, vol. 26, no. 1, pp. 173-180, 2011.

[28] J. Peñuelas, J. Sardans, J. Llusia et al., "Foliar chemistry and standing folivory of early and late-successional species in a Bornean rainforest," Plant Ecology and Diversity, vol. 6, no. 2, pp. 245-256, 2013.

[29] N. Rüger, C. Wirth, S. J. Wright, and R. Condit, "Functional traits explain light and size response of growth rates in tropical tree species," Ecology, vol. 93, no. 12, pp. 2626-2636, 2012.

[30] F. Valladares, E. Gianoli, and J. M. Gómez, "Ecological limits to plant phenotypic plasticity," New Phytologist, vol. 176, no. 4, pp. 749-763, 2007.

[31] S. E. Sultan, "Promising directions in plant phenotypic plasticity," Perspectives in Plant Ecology, Evolution and Systematics, vol. 6, no. 4, pp. 227-233, 2004.

[32] F. Valladares and R. W. Pearcy, "The functional ecology of shoot architecture in sun and shade plants of Heteromeles arbutifolia M. Roem., a Californian chaparral shrub," Oecologia, vol. 114, no. 1, pp. 1-10, 1998.
[33] D. Sánchez-Gómez, F. Valladares, and M. A. Zavala, "Functional traits and plasticity in response to light in seedlings of four Iberian forest tree species," Tree Physiology, vol. 26, no. 11, pp. 1425-1433, 2006.

[34] F. Valladares, A. Saldaña, and E. Gianoli, "Costs versus risks: architectural changes with changing light quantity and quality in saplings of temperate rainforest trees of different shade tolerance," Austral Ecology, vol. 37, no. 1, pp. 35-43, 2012.

[35] F. Valladares, S. J. Wright, E. Lasso, K. Kitajima, and R. W. Pearcy, "Plastic phenotypic response to light of 16 congeneric shrubs from a panamanian rainforest," Ecology, vol. 81, no. 7, pp. 1925-1936, 2000.

[36] Ü. Niinemets and F. Valladares, "Tolerance to shade, drought, and waterlogging of temperate northern hemisphere trees and shrubs," Ecological Monographs, vol. 76, no. 4, pp. 521-547, 2006.

[37] A. Paquette, A. Bouchard, and A. Cogliastro, "Morphological plasticity in seedlings of three deciduous species under shelterwood under-planting management does not correspond to shade tolerance ranks," Forest Ecology and Management, vol. 241, no. 1-3, pp. 278-287, 2007.

[38] Ü. Niinemets, "A review of light interception in plant stands from leaf to canopy in different plant functional types and in species with varying shade tolerance," Ecological Research, vol. 25, no. 4, pp. 693-714, 2010.

[39] S. Coste, J.-C. Roggy, G. Sonnier, and E. Dreyer, "Similar irradiance-elicited plasticity of leaf traits in saplings of 12 tropical rainforest tree species with highly different leaf mass to area ratio," Functional Plant Biology, vol. 37, no. 4, pp. 342-355, 2010.

[40] D. M. A. Rozendaal, V. H. Hurtado, and L. Poorter, "Plasticity in leaf traits of 38 tropical tree species in response to light; relationships with light demand and adult stature," Functional Ecology, vol. 20, no. 2, pp. 207-216, 2006.

[41] R.-G. Zang, W.-Y. Zhang, and Y. Ding, "Seed dynamics in relation to gaps in a tropical montane rainforest of Hainan Island, South China: (I) seed rain," Journal of Integrative Plant Biology, vol. 49, no. 11, pp. 1565-1572, 2007.

[42] L. Poorter, "Growth responses of 15 rain-forest tree species to a light gradient: the relative importance of morphological and physiological traits," Functional Ecology, vol. 13, no. 3, pp. 396410, 1999.

[43] J. M. G. Bloor and P. J. Grubb, "Morphological plasticity of shade-tolerant tropical rainforest tree seedlings exposed to light changes," Functional Ecology, vol. 18, no. 3, pp. 337-348, 2004.

[44] E. M. Veenendaal, M. D. Swaine, R. T. Lecha, M. F. Walsh, I. K. Abebrese, and K. Owusu-Afriyie, "Responses of West African forest tree seedlings to irradiance and soil fertility," Functional Ecology, vol. 10, no. 4, pp. 501-511, 1996.

[45] A. Mori and H. Takeda, "Functional relationships between crown morphology and within-crown characteristics of understory saplings of three codominant conifers in a subalpine forest in central Japan," Tree Physiology, vol. 24, no. 6, pp. 661-670, 2004.

[46] T. Toledo-Aceves and M. D. Swaine, "Above- and below-ground competition between the liana Acacia kamerunensis and tree seedlings in contrasting light environments," Plant Ecology, vol. 196, no. 2, pp. 233-244, 2008.

[47] N. J. B. Kraft, M. R. Metz, R. S. Condit, and J. Chave, "The relationship between wood density and mortality in a global tropical forest data set," New Phytologist, vol. 188, no. 4, pp. 11241136, 2010. 
[48] M. Larjavaara and H. C. Muller-Landau, "Rethinking the value of high wood density," Functional Ecology, vol. 24, no. 4, pp. 701705, 2010.

[49] S. Huang and G. Xie, "Xylophyta resource in Hainan Island, China (continuation IV)," Tropical Forestry, vol. 28, pp. 37-39, 2000.

[50] S. Huang and G. Xie, "Xylophyta resource in Hainan Island, China (continuation I)," Tropical Forestry, vol. 24, pp. 173-175, 1996.

[51] H. Poorter, K. J. Niklas, P. B. Reich, J. Oleksyn, P. Poot, and L. Mommer, "Biomass allocation to leaves, stems and roots: metaanalyses of interspecific variation and environmental control," New Phytologist, vol. 193, no. 1, pp. 30-50, 2012.

[52] G. Durigan, A. C. G. Melo, and J. S. Brewer, "The root to shoot ratio of trees from open- and closed-canopy cerrado in southeastern Brazil," Plant Ecology and Diversity, vol. 5, no. 3, pp. 333343, 2012.

[53] R. M. Gunton, L. J. Boyes, M. E. Griffiths, and M. J. Lawes, "Regeneration niches and functional traits of three common species in subtropical dune forest," Forest Ecology and Management, vol. 260, no. 9, pp. 1490-1497, 2010.

[54] M. Andrewsa, H. G. Mauleb, S. Hodgec, A. Cherrilla, and J. A. Ravend, "Seed dormancy, nitrogen nutrition and shade acclimation of impatiens glandulifera: implications for successful invasion of deciduous woodland," Plant Ecology and Diversity, vol. 2, no. 2, pp. 145-153, 2009.

[55] P. B. Reich, M. B. Walters, and D. S. Ellsworth, "Leaf life-span in relation to leaf, plant, and stand characteristics among diverse ecosystems," Ecological Monographs, vol. 62, no. 3, pp. 365-392, 1992.

[56] M. J. van de Wega, P. Meira, J. Gracea, and O. K. Atkinb, "Altitudinal variation in leaf mass per unit area, leaf tissue density and foliar nitrogen and phosphorus content along an Amazon-Andes gradient in Peru," Plant Ecology and Diversity, vol. 2, no. 3, pp. 243-254, 2009.

[57] P.-L. Mao, R.-G. Zang, Y. Ding, Y.-D. Li, and M.-X. Lin, "Photosynthetic characteristics of three typical tree species at different succession stages of a tropical montane rain forest on Hainan Island, China," Forest Research, vol. 24, no. 5, pp. 563571, 2011.

[58] P. J. Grubb, "A reassessment of the strategies of plants which cope with shortages of resources," Perspectives in Plant Ecology, Evolution and Systematics, vol. 1, no. 1, pp. 3-31, 1998.

[59] A. G. Gutiérrez, J. C. Aravena, N. V. Carrasco-Farías, D. A. Christie, M. Fuentes, and J. J. Armesto, "Gap-phase dynamics and coexistence of a long-lived pioneer and shade-tolerant tree species in the canopy of an old-growth coastal temperate rain forest of Chiloé Island, Chile," Journal of Biogeography, vol. 35, no. 9, pp. 1674-1687, 2008.

[60] F. Deng, R. Zang, and B. Chen, "Identification of functional groups in an old-growth tropical montane rain forest on Hainan Island, China," Forest Ecology and Management, vol. 255, no. 56, pp. 1820-1830, 2008.

[61] M. Zivcak, M. Brestic, Z. Balatova et al., "Photosynthetic electron transport and specific photoprotective responses in wheat leaves under drought stress," Photosynthesis Research, vol. 117, pp. 529-546, 2013.

[62] M. Brestic, M. Zivcak, H. M. Kalaji, R. Carpentier, and S. I. Allakhverdiev, "Photosystem II thermostability in situ: environmentally induced acclimation and genotype-specific reactions in Triticum aestivum L," Plant Physiology and Biochemistry, vol. 57, pp. 93-105, 2012.
[63] M. Zivcak, H. M. Kalaji, H. B. Shao, K. Olsovska, and M. Brestic, "Photosynthetic proton and electron transport in wheat leaves under prolonged moderate drought stress," Journal of Photochemistry and Photobiology B: Biology, 2014.

[64] J. Repková, M. Brestič, and K. Olšovská, "Leaf growth under temperature and light control," Plant, Soil and Environment, vol. 55, no. 12, pp. 551-557, 2009.

[65] M. Zivcak, M. Brestic, H. M. Kalaji, and Govindjee, "Photosynthetic responses of sun- and shade-grown barley leaves to high light: is the lower PSII connectivity in shad," Photosynthetic Research, vol. 119, no. 3, pp. 339-354, 2014. 

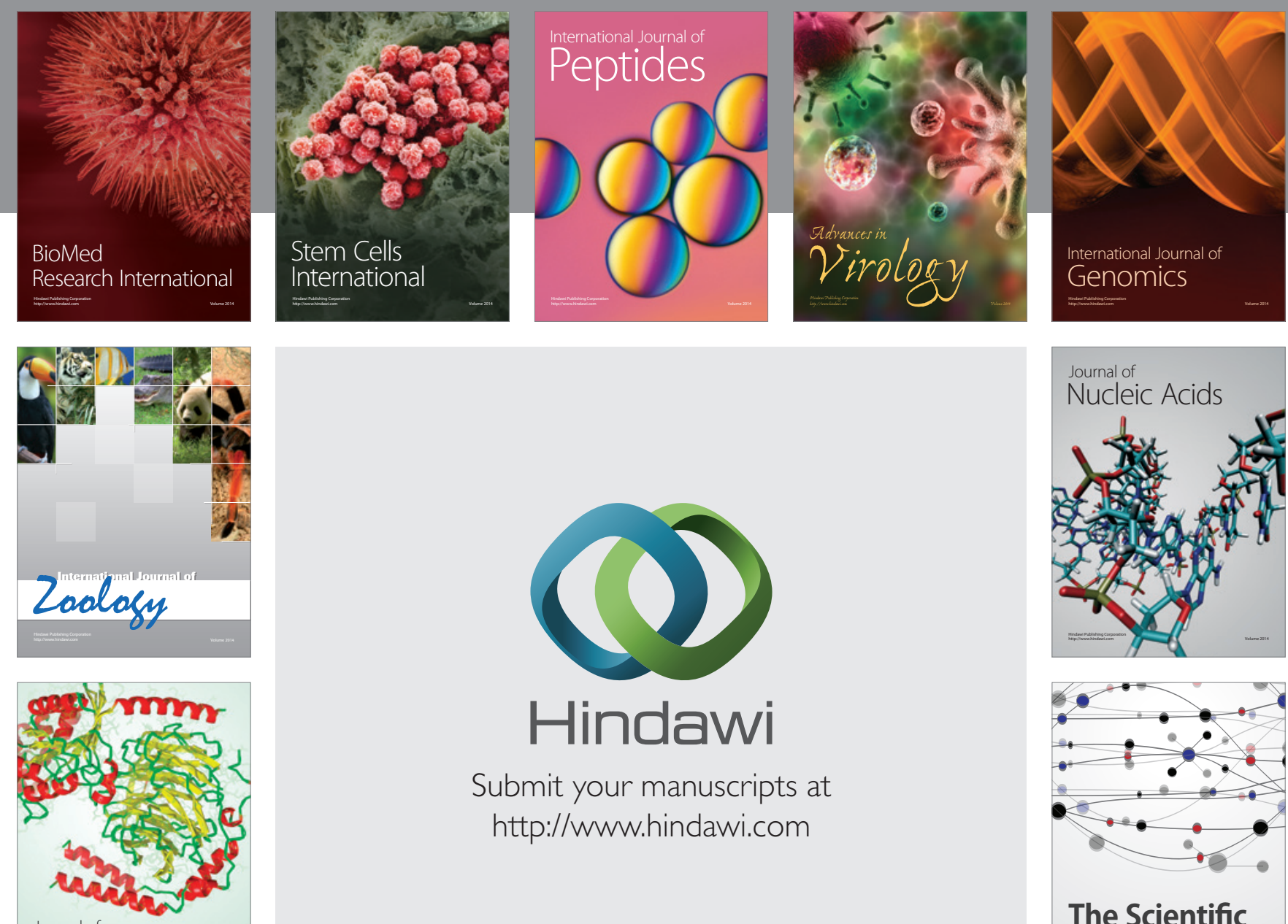

Submit your manuscripts at

http://www.hindawi.com

Journal of
Signal Transduction
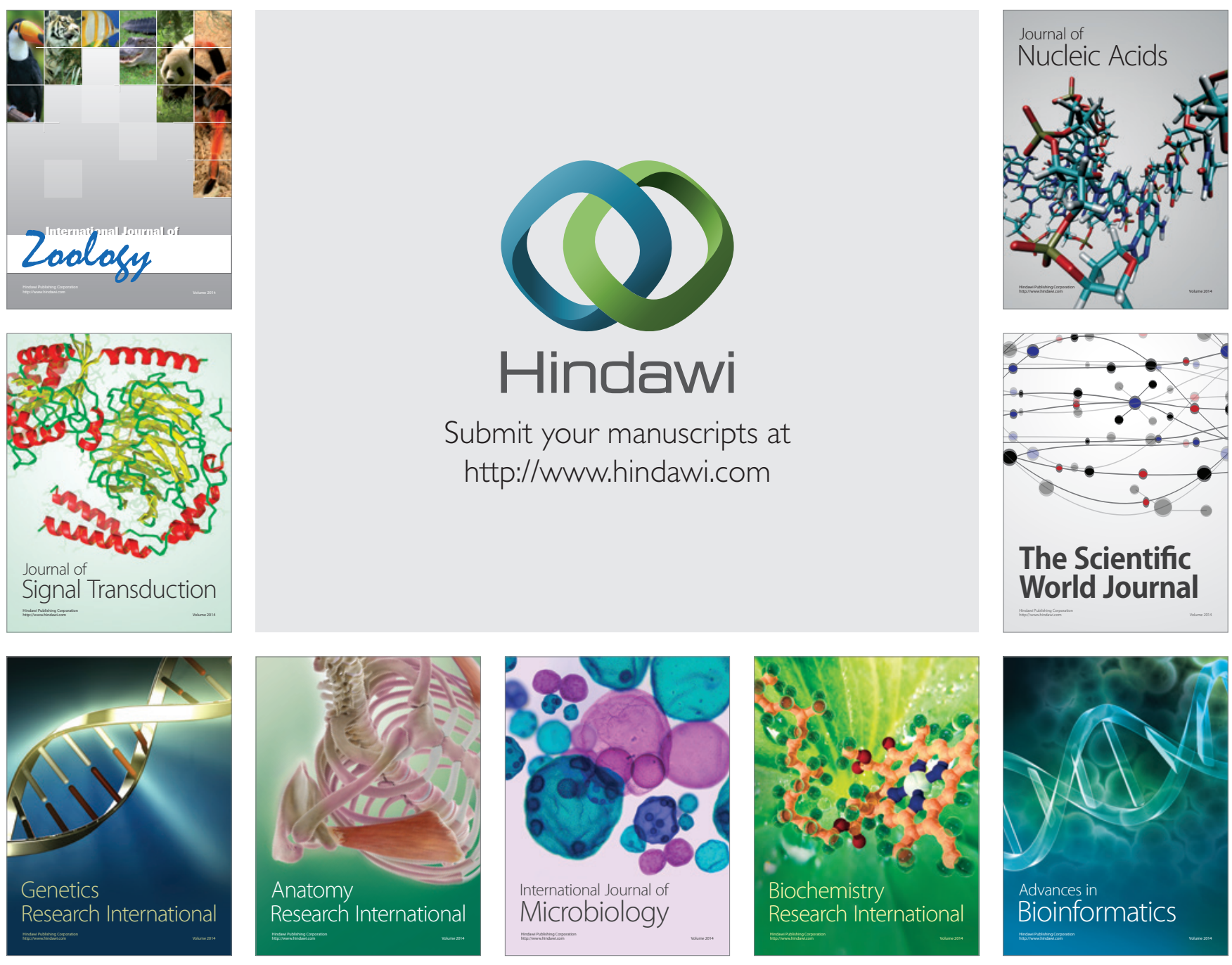

The Scientific World Journal
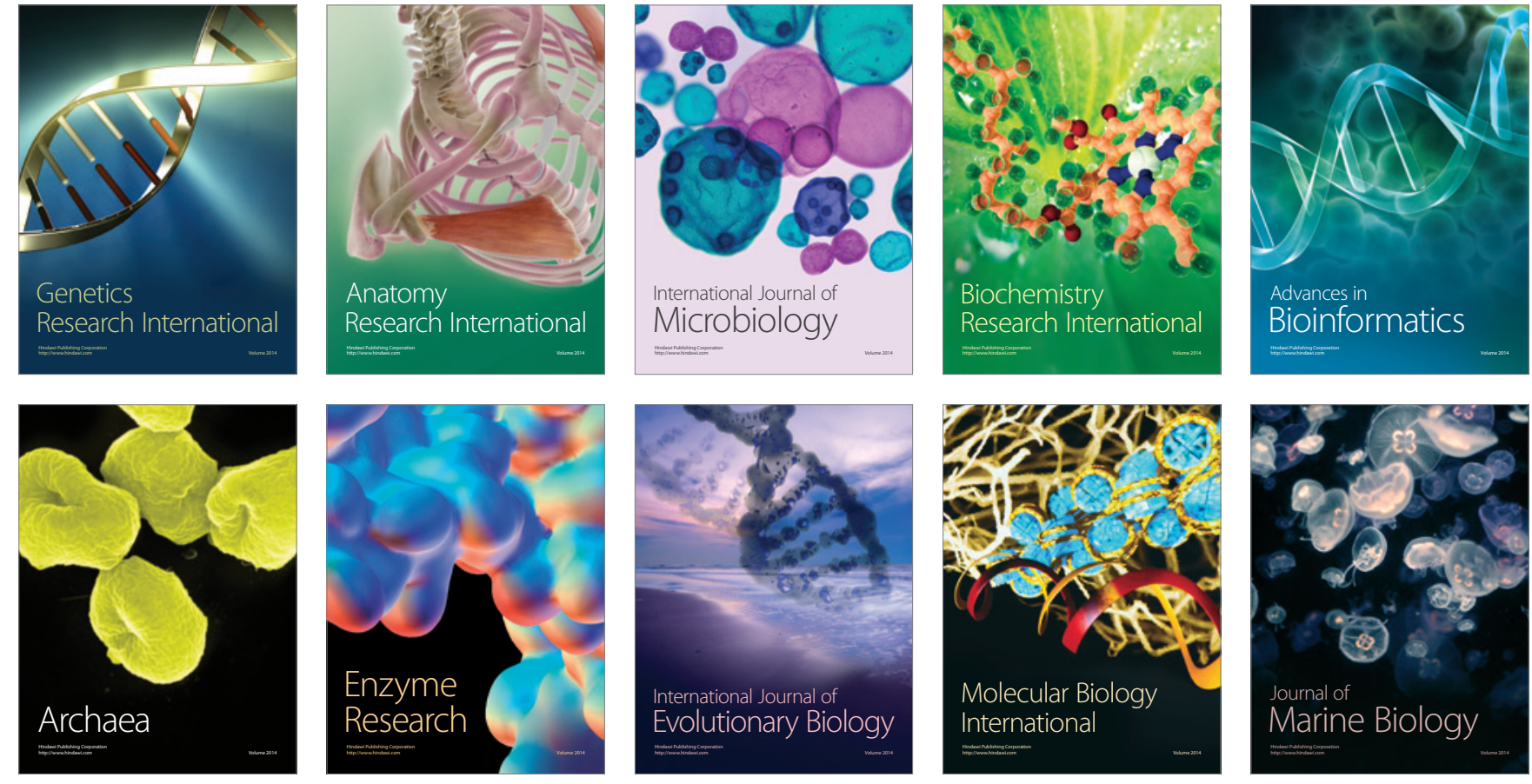